\title{
Evaluation of the Effect of Pulmonary Vein Isolation Treatment With Left Atrial Catheter Ablation Method on Atrial Conduction Times in Patients With Paroxysmal Atrial Fibrillation
}

Ibrahim Donmez ( $\boldsymbol{\sigma}$ dr_ibrahimdonmez@hotmail.com )

Bolu Abant Izzet Baysal Universitesi Tip Fakultesi https://orcid.org/0000-0002-6913-9073

Fatma Hizal Erdem

Bolu Abant Izzet Baysal Universitesi Tip Fakultesi

Tolga Memioğlu

Bolu Abant Izzet Baysal Universitesi Tip Fakultesi

Emrah Acar

Bolu Abant Izzet Baysal Universitesi Tip Fakultesi

\section{Original Article}

Keywords: Pulmonary vein isolation, Radiofrequency ablation, Atrial conduction time, Tissue doppler echocardiography

Posted Date: February 5th, 2021

DOI: https://doi.org/10.21203/rs.3.rs-167274/v1

License: (9) This work is licensed under a Creative Commons Attribution 4.0 International License. Read Full License 


\section{Abstract}

\section{Purpose}

Atrial fibrillation (AF) causes structural, electrical, and cellular remodeling in the atrium. Evaluation of intra- and interatrial conduction time, which is measured by tissue doppler echocardiography, indicates structural and electrical remodeling in the atrium. In the meta-analysis of the studies investigating rhythm control treatment strategy in paroxysmal atrial fibrillation; radiofrequency (RF) ablation has been shown to be superior over antiarrhythmics in ensuring and protecting sinus rhythm. The aim of this study was to evaluate the effect of pulmonary vein isolation applied with RF ablation therapy on intra- and interatrial conduction time and to investigate the structural and electrically remodeling after treatment.

Methods

Fifty-two patients with symptomatic PAF despite at least one antiarrhythmic drug and without structural heart disease were included in the study. Two patients were excluded because of complications developed during and after the operation. Fifty patients ( 28 female; mean age: $51.68 \pm 11.731$; mean left atrial diameter: $36.79 \pm 4.318$ ) who underwent $\mathrm{CARTO}{ }^{\circledR} 3 \mathrm{D}$ pulmonary vein isolation applied with the RF ablation system were followed-up. Intra- and the inter-atrial electromechanical delay was measured in all patients by tissue doppler echocardiography before and three months after RF ablation.

Results

All intra- and interatrial conduction times were significantly decreased 3 months after RF ablation procedure (PA lateral $p=0.022$; PA septum $p=0.002$; PA tricuspid $p=0.019$, interatrial conduction delay $p=0,012$, intra-atrial conduction delay $p=0.029$ ).

\section{Conclusion}

The results of our study suggest that providing stable sinus rhythm by the elimination of the AF triggering mechanisms with RF ablation of pulmonary vein isolation may slow down, stop or even improve structural remodeling at substrate level secondary to AF even in patients who did not yet develop atrial fibrosis and permanent structural changes.

\section{Introduction}

Atrial fibrillation (AF) is a supraventricular tachyarrhythmia resulting from the irregular activity of the atria and is characterized by the atrial mechanic functional loss[1]. The ventricular rate is variable and irregular depending on the conduction function of the atrioventricular node. On electrocardiogram, rapid, irregular, fibrillation waves of different shapes and sizes are seen instead of $P$ waves[2].

In the developed countries, the prevalence of AF is estimated between $1.5-2 \%$ in the general population and the mean age of patients with this disease is steadily increasing. Today, the mean age of AF patients 
is between 75 and 85 years. This arrhythmia is associated with a five-fold increase in the risk of stroke, a three-fold increase in the incidence of congestive heart failure, and high mortality. Hospitalization is common among AF patients. This arrhythmia is an important cardiovascular problem in modern society and its medical, social and economical aspects will further worsen in the next decades[3]. AF usually starts as paroxysmal AF (PAF) and transforms into persistent AF[4]. The mechanism of PAF consists of initiating factors $[5,6]$.

Two main targets in AF treatment are protection against thromboembolic complications, and rate and/or rhythm control. Appropriate treatment methods to control the symptoms or prevent cardiomyopathy that may occur due to tachycardia are similar. The use of warfarin or new generation oral anticoagulants in eligible patients reduces the risk of stroke. Among two important studies comparing rhythm and rate control, in the randomized controlled AFFIRM

(Atrial Fibrillation Follow-up Investigation of Rhythm Management) study no difference could be demonstrated between the two groups in terms of mortality and stroke from all causes [7]. In the RACE (Rate Control versus Electrical cardioversion for persistent atrial fibrillation) study, it was shown that rate control was not worse than rhythm control in the prevention of cardiovascular mortality and morbidity [8]. However, in the subgroup analysis of the RACE study, left ventricular function was shown to worsen less or even to improve in patients with heart failure and rhythm control with catheter ablation for AF $[9,10]$. Long-term rhythm control can be achieved with antiarrhythmics or ablation. In a meta-analysis of studies investigating rhythm control in paroxysmal $\mathrm{AF}$, ablation was shown to be superior over antiarrhythmics in ensuring and maintaining sinus rhythm $[11,12]$. Ablation can be performed in patients who are symptomatic despite optimal medical therapy $[13,14]$.

Atrial fibrillation is thought to occur as a result of the combination of electrophysiological, metabolic, ischemic, hemodynamic, and genetic factors $[15,16]$. Persistent AF causes electrical remodeling characterized by shortening of atrial refractoriness caused by changes in the expression of ion channels in the atria, contractile remodeling resulting in disruption of atrial contraction, and structural remodeling leading to changes in the cellular structure of atrial myocytes. All these changes affect each other, leading to continuity of the AF process [15]. While electrical activity foci in the pulmonary vein (PV) cause the development of $A F$, structural changes occurring in the left atrium due to chronic or recurrent $A F$ cause remodeling lead to especially fibrosis and continuing rhythm disturbance $[17,18]$. Atrial conduction time that can be easily measured simply by tissue Doppler echocardiography can give us an idea about the arrhythmogenic substrate changes that make AF sustained $[19,20]$. The objective of this study was to evaluate the effect of PV electrical activity foci isolation treatment with RF ablation method on the left atrial arrhythmogenic substrate through tissue

Doppler echocardiography and to investigate the structural remodeling process due to AF by the termination of electrical remodeling using RF ablation method.

\section{Materials And Methods}


A total of 52 patients aged $\geq 18$ years, who presented to and/or were hospitalized in the Abant lzzet Baysal University Medical Faculty, cardiology outpatient clinic, diagnosed with paroxysmal AF and who were symptomatic despite at least one antiarrhythmic drug were included in the study. Two patients were excluded from the study due to complications developed during and after the procedure. A detailed physical examination and 12-lead ECG were performed on all patients. All patients underwent transthoracic echocardiography before the procedure and transesophageal echocardiography within 48 hours before the procedure to confirm the absence of left atrial appendage (LAA) thrombus. Intra- and the inter-atrial electromechanical delay was studied with tissue Doppler method 3 months after the procedure. Identification of $\mathrm{AF} \geq 30$ seconds following the procedure was considered a failure.

Patients with an acute coronary syndrome, previous myocardial infarction (MI) and coronary artery disease, congestive heart failure, decreased LV ejection fraction ( $E F<55 \%)$, chronic obstructive pulmonary disease, significant valvular disease, pacemaker implantation, hypertension (resting blood pressure $\geq$ $140 / 90 \mathrm{~mm} \mathrm{Hg}$ ), diabetes mellitus, peripheral vascular diseases, respiratory or neurologic disorders, pericarditis, congenital heart disease, alcohol addiction, renal or hepatic disease and those with poor echocardiographic imaging were excluded from the study.

Before the beginning, the study protocol was approved by the local ethics committee of our hospital. All patients were informed about the objectives of the study in detail and

gave informed signed consent forms. The study was conducted in accordance with the ethical principles of the Declaration of Helsinki.

\subsection{Echocardiographic Examination and Measurement of Atrial Conduction Time Echocardiographic} examination was performed in all patients before pulmonary vein RF ablation and 3 months after the ablation with GE VividS6 system (GE Vingmed, Horten, Norway) using a probe of 2-4 MHz frequency. Echocardiographic examination was performed with the patient in the supine position and lying on the left side, using appropriate echocardiographic windows with $\mathrm{M}$ mode, two-dimensional (2D), pulse wave doppler, continuous wave doppler, color flow, and tissue doppler imaging (TDI)

2.2 M-mode echocardiography: Right ventricular end-systole and diastole sizes and ejection fraction, enddiastole septum and posterior wall thicknesses, and left atrial end-diastole dimensions were measured with M-mode

2.3 2D echocardiography: Wall motion of both ventricles, valvular structure and functions, and pericardial window were examined with 2D echocardiography. Mitral flow parameters were measured at the end of expiration by averaging three cardiac

2.4 Tissue Doppler Echocardiography: Simultaneous ECG recordings were taken during tissue Doppler echocardiographic examination. The time from the beginning of the P wave on the ECG to the onset of the A' wave in tissue Doppler (wave indicating atrial contraction) was defined as the PA distance (atrial electromechanical time) (Fig 1). Atrial electromechanical time was measured separately from the lateral 
mitral annulus, septal mitral annulus, and lateral tricuspid annulus; and defined as PA lateral, PA septum, and PA tricuspid, respectively. The difference between PA lateral and PA tricuspid (PA lateral

- PA tricuspid) was defined as interatrial conduction delay; and the difference between PA septum and PA tricuspid (PA septum - PA tricuspid) as intraatrial conduction delay.

2.5 Transesophageal Echocardiography: All patients underwent TEE with in 48 hours

before the ablation. The echogenic mass in the LAA that continued in more than one plane and distinguished from the surrounding tissues was considered thrombus, and patients with thrombus in the LAA were excluded.

\subsection{Electrophysiological Procedure}

Pulmonary vein isolation was performed under anesthesia and noninvasive mild sedation. Vascular access was obtained using the bilateral femoral veins and left femoral artery. Intracardiac and superficial electrocardiograms were recorded at a rate of $100 \mathrm{~mm} /$ seconds (Prucka, GE Medical Systems). Transseptal punctures were made with the Brockenbrough needle transseptal needle (St. Jude Medical, Minnetonka, MN, USA) under fluoroscopy. First, pulmonary vein electrical mapping was performed with a circular mapping catheter (Lasso, Biosense Webster, Diamond Bar, CA, USA) via the single transseptal sheath and pulmonary vein potentials (it was paced from the coronary sinus to separate from atrial potential [AP]) were determined. The ablation catheter (SF-Contact force, Biosense Webster, Diamond Bar, CA, USA) was inserted through the other transseptal sheath, right and left pulmonary vein isolation was performed, respectively. (Fig 2)

\subsection{Statistical Analysis}

Biostatistical analysis of the data obtained was performed with SPSS (Statistical Package for Social Sciences) for Windows v. 21.0 package software. The normality of the data was analyzed with the Kolmogorov-Smirnov test. Continuous variables were expressed as mean \pm standard deviation and categorical variables with frequency and percentage (\%). Descriptive statistics regarding normally distributed variables were expressed as mean \pm standard deviation. Whereas, non-normally distributed variables were given with median, minimum, and maximum values. In the statistical evaluations, correlations between

categorical variables were examined with the Chi-square test, while Pearson's correlation analysis was used to determine the direction and level of the correlations between the variables. Normally distributed variables were analyzed using Student $t$ test, and non-normally distributed variables were analyzed using Mann-Whitney $U$ and Kruskal-Wallis tests. $p<0.05$ values considered statistically significant.

\section{Results}

A total of 52 patients with PAF despite at least one antiarrhythmic drug were included. One patient developed acute pericardial tamponade during 3D pulmonary vein isolation and the process was 
terminated. The patient underwent emergency percutaneous pericardiocentesis, but the patient was taken to the surgery since pericardiocentesis was not sufficient. LAA perforation was observed and the operated patient had no problem postoperatively. In another patient, pericardial tamponade was observed 12 hours after the successful process and upon percutaneous pericardiocentesis was insufficient due to effusion localization, the patient was taken to the surgery and followed-up without problem after the operation. Finally, 50 patients who underwent RF ablation with the CARTO ${ }^{\circledR} 3 \mathrm{D}$ pulmonary vein isolation system were analyzed. All patients had received at least one antiarrhythmic drug with $34(68 \%)$ had received propafenone and the remaining $16(32 \%)$ amiodarone. Cryoablation was attempted in two (4\%) patients and none of them had structural heart disease. Right hemianopsia without loss of strength was found in one patient after the ablation, cranial diffusion MRI was ordered and micro-embolism foci were detected.

Of all patients, $28(56 \%)$ were female and the mean age of the patients was $51.68 \pm 11.731$ years. PAF attack was observed at follow-up after the ablation in six (12\%) patients. Basal echocardiographic findings of the patients are given in Table 1.

Table 1 Basal echocardiographic findings of the patients.

\begin{tabular}{|llll|}
\hline & Minimum & Maximum & Mean \\
\hline LVEDD & 38 & 57 & $49.30 \pm 4.138$ \\
\hline LVESD & 20 & 38 & $29.70 \pm 4.170$ \\
\hline IVS & 7 & 14 & $9.64 \pm 1.495$ \\
\hline PW & 7 & 13 & $9.36 \pm 1.241$ \\
\hline EF & 56 & 67 & $64.91 \pm 2.057$ \\
\hline LA & 27 & 47 & $36.79 \pm 4.318$ \\
\hline Dt & 92 & 279 & $183.36 \pm 41.711$ \\
\hline IVRT & 46 & 133 & $85.37 \pm 19.733$ \\
\hline ICT & 52 & 130 & $79.09 \pm 17.251$ \\
\hline ET & 214 & 330 & $268.00 \pm 29.658$ \\
\hline Tei INDEKS & 0.303 & 0.8832 & $0.620284 \pm 0.131674$ \\
\hline E & 38 & 101 & $67.50 \pm 15.688$ \\
\hline A & 35 & 103 & $63.95 \pm 16.669$ \\
\hline Et & 4 & 18 & $8.93 \pm 3.029$ \\
\hline At & 4 & 16 & $9.24 \pm 2.618$ \\
\hline
\end{tabular}


LVEDD: Left ventricular end diastolic diameter, LVESD: Left ventricular end systolic diameter, IVS:Interventricular septum, PW: Posterior wall, EF: Ejection Fraction, LA: Left atrium size, Dt; Deceleration time, IVRT: Interventricular relaxation time, ICT: Interventricular Contraction Time, ET: Ejection Time , E: Mitral valve early diastolic peak rate, A: Mitral valve late diastolic peak rate, Em: Early diastolic myocardial rate, Am: Late diastolic myocardial rate.

Table 2 Comparison of atrial conduction times measured with tissue Doppler method.

\begin{tabular}{lcccc}
\hline & Before ablation & $\begin{array}{c}\text { 3 months after } \\
\text { ablation }\end{array}$ & $\begin{array}{c}\text { Difference } \\
\text { between } \\
\text { before and } \\
\text { after }\end{array}$ & P values \\
& & & ablation & \\
\hline PA lateral (ms) & $72.90 \pm 15.3$ & $68.41 \pm 12.37$ & $4.48 \pm 1.84$ & 0.022 \\
PA septum (ms) & $49.17 \pm 10.21$ & $44.75 \pm 7.30$ & $4.41 \pm 1.28$ & 0.002 \\
$\begin{array}{l}\text { PA tricuspid } \\
\text { (ms) }\end{array}$ & $35.55 \pm 7.92$ & $33.37 \pm 5.62$ & $2.17 \pm 0.87$ & 0.019 \\
$\begin{array}{l}\text { Interatrial } \\
\text { conduction delay }\end{array}$ & $35.11 \pm 12.13$ & $29.70 \pm 10.70$ & $5.40 \pm 1.99$ & 0.012 \\
$\begin{array}{l}\text { Intra-atrial } \\
\text { conduction delay }\end{array}$ & $13.74 \pm 5.93$ & $11.37 \pm 5.37$ & $2.37 \pm 1.02$ & 0.029 \\
\hline
\end{tabular}

PA: Time from the beginning of the P wave on the ECG to the onset of the $A^{\prime}$ wave in tissue Doppler (wave indicating atrial contraction)

PA lateral, PA septum, PA tricuspid, intra- and interatrial conduction delay times were significantly decreased after the RF ablation procedure Fig 3.

In the correlation analysis of atrial conduction times before and after RF ablation; a significant negative correlation was found in all values including PA lateral $(r=-0.763 ; p<0.001)$, PA septum $(r=-0.734 ; p<0.01)$, PA tricuspid $(r=-0.812 ; p<0.001)$, interatrial conduction time $(r=-0.594 ; p=0.00)$ and intra-atrial conduction time $(r=-0.563 ; p=0.002)$. 
Comparison of atrial conduction times before and after ablation according to sexes is shown in Table 3 . Table 3 Comparison of pre- and post-ablation atrial conduction times according to sexes.

\begin{tabular}{lccc}
\hline & $\begin{array}{c}\text { Before } \\
\text { ablation }\end{array}$ & 3 months after ablation & $\begin{array}{c}\text { P } \\
\text { values }\end{array}$ \\
\hline MALE & & & \\
\hline PA lateral (ms) & $69,60 \pm 20,522$ & $65,700 \pm 15,319$ & 0,401 \\
PA septum (ms) & $48,40 \pm 13,914$ & $43,60 \pm 8,448$ & 0,133 \\
PA tricuspid (ms) & $36,80 \pm 10,799$ & $33,30 \pm 6,617$ & 0,158 \\
Interatrial conduction delay (ms) & $30,60 \pm 14,065$ & $24,70 \pm 8,472$ & 0,214 \\
\hline Intraatrial conduction delay (ms) & $11,60 \pm 5,892$ & $10,10 \pm 4,332$ & 0,325 \\
\hline
\end{tabular}

FEMALE

PA lateral (ms)

$74,63 \pm 12,015 \quad 69,842 \pm 10,704$

0,011

PA septum (ms)

$49,58 \pm 8,064$

$45,368 \pm 6,80$

0,005

PA tricuspid (ms)

$34,89 \pm 6,172$

$33,421 \pm 5,231$

0,026

Interatrial conduction delay (ms)

$37,76 \pm 10,377$

$32,647 \pm 11,005$

0,018

Intra-atrial conduction delay (ms)

$15,00 \pm 5,766$

$12,117 \pm 5,904$

0,057

When atrial conduction times before and after RF ablation were compared according to sexes; no significant difference was found between the two group in male patients, while there was a significant difference in all parameters except for intra-atrial conduction delay in female patients (Fig 4). 
When left atrial diameter and the parameters investigated in this study were evaluated with Pearson's correlation analysis; there was no significant correlation between left atrial diameter and post-ablation PA lateral $(r=0.153 ; p=0.320)$, PA septum $(r=0.61 ; p=0.695)$, PA tricuspid $(r=0.66 ; p=0.670)$, interatrial conduction delay $(r=0.169 ; p=0,279)$, and post-ablation PA lateral $(r=0,156 ; p=0,402)$, PA septum $(r=0.10$; $p=0,960)$, PA tricuspid $(r=0,015 ; p=0,956)$, interatrial conduction delay $(r=-0.009 ; p=0,960)$ and intra-atrial conduction delay $(r=0.001 ; p=0,991)$.

\section{Discussion}

$\mathrm{AF}$ is a disease characterized by the disruption of cardiac mechanical functions due to irregular atrial activation. There are initiating factors that cause the onset of $\mathrm{AF}$ and an anatomical substrate that maintains it. An important feature of $A F$ is to $A n$ important feature of $A F$ is that the arrhythmia sustains itself when it begins. This is possibly caused by remodeling occurring in the atrium. Atrial remodeling occurs at electrophysiological, cellular, and anatomic levels [21, 15]. Many studies have shown the association between intra- and interatrial conduction blocks and AF [22, 23]. It is thought that a shortening in the atrial effective refractory period, inconsistency of the atrial effective refractory period with changes in heart rate, and a prolongation in atrial conduction time occur as a result of electrical remodeling in AF [24]. Delay in interatrial and intra-atrial conduction causes atrial refractoriness to be inhomogeneous.

In a study by Deniz et al. [25], it was shown that left intra-atrial mechanical delay increased in patients with PAF and it was an independent risk factor of PAF. Kumagai et al [26] showed that inter and intraatrial conduction was prolonged following electrical cardioversion in patients with lone AF. In a study by Evranos et al. [27] with patients who underwent cryoballoon, the intra-atrial delay before and 3 months after the procedure was found to be a predictor of late AF recurrence.

There may be fibrosis in the left atrium in AF, which causes anisotropy, maintain anisotropic atrial conduction delay, changes intra-atrial refractoriness, and leads to the continuity of reentrant arrhythmia. The persistence of AF during the structural atrial remodeling process leads to a reduction in the amount of connexin 40 and thus causing regional conduction abnormalities that lead to reentrant pathways to maintain themselves [28]. Radiofrequency (RF) catheter ablation has recently been introduced as an important therapeutic option in patients with drug-resistant atrial fibrillation (AF), with about a $75 \%$

success rate $[29,30]$. In our study, significant decreases were observed in intra- and interatrial conduction times after RF ablation (PA lateral p: 0.022; PA septum p: 0.002; PA tricuspid p: 0.019; interatrial conduction delay p:0.012; and intra-atrial conduction delay p:0.029). This result suggests that providing stable sinus rhythm by the elimination of the AF triggering mechanisms with RF ablation of pulmonary vein isolation may slow down, stop or even improve structural remodeling at substrate level secondary to AF even in patients who did not yet develop atrial fibrosis and permanent structural changes. There is a linear relationship between electrophysiological, structural, and cellular remodeling with the increase of AF duration during the day in PAF patients, and this process progresses towards permanent AF [15]. 
However, it is unclear whether AF can produce additional forms of remodeling, especially when arrhythmia remains sustained for long periods [31]. As also seen in our study, preservation of sinus rhythm after pulmonary vein RF ablation is expected to affect this process.

Sex differences may affect diagnostic and therapeutic interventions in a wide variety of medical conditions including cardiac arrhythmias [32]. In our study, when atrial conduction times were compared before and after RF ablation according to sexes; no significant difference was observed between the two groups in male patients, while there were significant differences in all parameters except for intra-atrial conduction delay in female patients. The reason was probably due to the low number of male patients (14 patients; $28 \%$ ) who had atrial conduction time measurement after the procedure.

\section{Study Limitations}

In this study, the number of patients was relatively small. Long-term results could be better analyzed with a larger series of patients and longer follow-up. Clearer information about fibrosis and left atrial structural changes could be obtained with the addition of cardiac MRI in addition to echocardiography.

\section{Conclusion}

As the clinical emphasis in this study; successful RF ablation eliminates initiating mechanisms and provides significant positive gains in a complex cardiovascular disease like AF. Intra- and inter-atrial conduction times that are considered indicators of this significantly decreased after ablation. This result increases the expectation of a decrease in complications related to AF in addition to rhythm control after a successful RF ablation.

\section{Declarations}

Acknowledgements: N/A

Conflicts of interest/Competing interests: The authors report no conflict of interest regarding this study.

Funding: This study did not receive financial support

Informed Consent: All participants were informed about the objectives of the study and signed informed consent forms.

Availability of data and material: All data used in this study are included in the manuscript.

\section{References}

1. Crystal E, Connolly SJ. Atrial fibrillation: guiding lessons from epidemiology. Cardiology clinics. 2004;22(1):1-8. 
2. Fuster V, Rydén LE, Cannom DS, Crijns HJ, Curtis AB, Ellenbogen KA et al. Acc/aha/esc 2006 guidelines for the management of patients with atrial fibrillation: A report of the american college of cardiology/american heart association task force on practice guidelines and the european society of cardiology committee for practice guidelines (writing committee to revise the 2001 guidelines for the management of patients with atrial fibrillation): Developed in collaboration with the european heart rhythm association and the heart rhythm society. Circulation. 2006;114(7):e257-e354.

3. Members ATF, Camm AJ, Lip GY, De Caterina R, Savelieva I, Atar D et al. 2012 focused update of the ESC Guidelines for the management of atrial fibrillation: an update of the 2010 ESC Guidelines for the management of atrial fibrillation Developed with the special contribution of the European Heart Rhythm Association. European heart journal. 2012;33(21):2719-47.

4. Kato T, Yamashita T, Sagara K, linuma H, Fu L-T. Progressive nature of paroxysmal atrial fibrillation. Circulation Journal. 2004;68(6):568-72.

5. Fujiki A. Progression of atrial fibrillation from paroxysmal to persistent. Circulation Journal. 2014;78(5):1058-60.

6. Wyse DG, Gersh BJ. Atrial fibrillation: a perspective: thinking inside and outside the box. Circulation. 2004;109(25):3089-95.

7. Wyse D, Waldo A, DiMarco J, Domanski M, Rosenberg Y, Schron E et al. Atrial Fibrillation Follow-up Investigation of Rhythm Management I. A comparison of rate control and rhythm control in patients with atrial fibrillation. N Engl J Med. 2002;347(23):1825-33.

8. Van Gelder IC, Hagens VE, Bosker HA, Kingma JH, Kamp O, Kingma T et al. A comparison of rate control and rhythm control in patients with recurrent persistent atrial fibrillation. New England Journal of Medicine. 2002;347(23):1834-40.

9. Hsu L-F, Jaïs P, Sanders P, Garrigue S, Hocini M, Sacher F et al. Catheter ablation for atrial fibrillation in congestive heart failure. New England Journal of Medicine. 2004;351(23):2373-83.

10. Khan MN, Jaïs P, Cummings J, Di Biase L, Sanders P, Martin DO et al. Pulmonary-vein isolation for atrial fibrillation in patients with heart failure. New England Journal of Medicine. 2008;359(17):177885.

11. Wilber DJ, Pappone C, Neuzil P, De Paola A, Marchlinski F, Natale A et al. Comparison of antiarrhythmic drug therapy and radiofrequency catheter ablation in patients with paroxysmal atrial fibrillation: a randomized controlled trial. Jama. 2010;303(4):333-40.

12. Pappone C, Augello G, Sala S, Gugliotta F, Vicedomini G, Gulletta S et al. A randomized trial of circumferential pulmonary vein ablation versus antiarrhythmic drug therapy in paroxysmal atrial fibrillation: the APAF Study. Journal of the American College of Cardiology. 2006;48(11):2340-7.

13. Camm AJ, Kirchhof P, Lip GY, Schotten U, Savelieva I, Ernst S et al. Erratum: Guidelines for the management of atrial fibrillation (European Heart Journal (2010) 31 (2369-2429)). European Heart Journal. 2011;32(9):1172.

14. Calkins H, Brugada J, Packer DL, Cappato R, Chen S-A, Crijns HJ et al. HRS/EHRA/ECAS Expert Consensus Statement on Catheter and Surgical Ablation of Atrial Fibrillation: Recommendations for 
Personnel, Policy, Procedures and Follow-Up: A report of the Heart Rhythm Society (HRS) Task Force on Catheter and Surgical Ablation of Atrial Fibrillation Developed in partnership with the European Heart Rhythm Association (EHRA) and the European Cardiac Arrhythmia Society (ECAS); in collaboration with the American College of Cardiology (ACC), American Heart Association (AHA), and the Society of Thoracic Surgeons (STS). Endorsed and Approved by the governing bodies of the American College of Cardiology, the American Heart Association, the European Cardiac Arrhythmia Society, the European Heart Rhythm Association, the Society of Thoracic Surgeons, and the Heart Rhythm Society. Europace. 2007;9(6):335-79.

15. Allessie M, Ausma J, Schotten U. Electrical, contractile and structural remodeling during atrial fibrillation. Cardiovascular research. 2002;54(2):230-46.

16. Shiroshita-Takeshita A, Brundel BJ, Nattel S. Atrial fibrillation: basic mechanisms, remodeling and triggers. Journal of Interventional Cardiac Electrophysiology. 2005;13(3):181-93.

17. Kopecky SL, Gersh BJ, McGoon MD, Whisnant JP, Holmes Jr DR, Ilstrup DM et al. The natural history of lone atrial fibrillation. New England Journal of Medicine. 1987;317(11):669-74.

18. Haissaguerre M, Jaïs P, Shah DC, Takahashi A, Hocini M, Quiniou G et al. Spontaneous initiation of atrial fibrillation by ectopic beats originating in the pulmonary veins. New England Journal of Medicine. 1998;339(10):659-66.

19. Rein AJ, O'Donnell CP, Colan SD, Marx GR. Tissue velocity Doppler assessment of atrial and ventricular electromechanical coupling and atrioventricular time intervals in normal subjects. The American journal of cardiology. 2003;92(11):1347-50.

20. Deniz A, Yavuz B, Ciftci O. Left atrial conduction time detected by tissue Doppler imaging increases in paroxysmal atrial fibrillation patients. Clin Cardiol. 2006;29(suppl):IIl-27.

21. Ausma J, Wijffels M, Thoné F, Wouters L, Allessie M, Borgers M. Structural changes of atrial myocardium due to sustained atrial fibrillation in the goat. Circulation. 1997;96(9):3157-63.

22. Platonov P, Yuan S, Hertervig E, Kongstad O, Roijer A, Vygovsky A et al. Further evidence of localized posterior interatrial conduction delay in lone paroxysmal atrial fibrillation. EP Europace. 2001;3(2):100-7.

23. Simpson Jr RJ, Amara I, Foster JR, Woelfel A, Gettes LS. Thresholds, refractory periods, and conduction times of the normal and diseased human atrium. American Heart Journal. 1988;116(4):1080-90.

24. Wijffels MC, Kirchhof CJ, Dorland R, Allessie MA. Atrial fibrillation begets atrial fibrillation: a study in awake chronically instrumented goats. Circulation. 1995;92(7):1954-68.

25. Deniz A, Yavuz B, Aytemir K, Hayran M, Kose S, Okutucu S et al. Intra-left atrial mechanical delay detected by tissue Doppler echocardiography can be a useful marker for paroxysmal atrial fibrillation. Echocardiography. 2009;26(7):779-84.

26. Kumagai K, Akimitsu S, Kawahira K, Kawanami F, Yamanouchi Y, Hiroki T et al. Electrophysiological properties in chronic lone atrial fibrillation. Circulation. 1991;84(4):1662-8. 
27. Evranos B, Aytemir K, Oto A, Okutucu S, Karakulak U, Şahiner L et al. Predictors of atrial fibrillation recurrence after atrial fibrillation ablation with cryoballoon. Cardiology journal. 2013;20(3):294-303.

28. Wilhelm M, Kirste W, Kuly S, Amann K, Neuhuber W, Weyand M et al. Atrial distribution of connexin 40 and 43 in patients with intermittent, persistent, and postoperative atrial fibrillation. Heart, Lung and Circulation. 2006;15(1):30-7.

29. Fisher JD, Spinelli MA, Mookherjee D, Krumerman AK, Palma EC. Atrial fibrillation ablation: reaching the mainstream. Pacing and clinical electrophysiology. 2006;29(5):523-37.

30. Cappato R, Calkins H, Chen S-A, Davies W, lesaka Y, Kalman J et al. Worldwide survey on the methods, efficacy, and safety of catheter ablation for human atrial fibrillation. Circulation. 2005;111(9):1100-5.

31. Burstein B, Qi X-Y, Yeh Y-H, Calderone A, Nattel S. Atrial cardiomyocyte tachycardia alters cardiac fibroblast function: a novel consideration in atrial remodeling. Cardiovascular research. 2007;76(3):442-52.

32. Curtis AB, Narasimha D. Arrhythmias in women. Clinical cardiology. 2012;35(3):166-71.

\section{Figures}

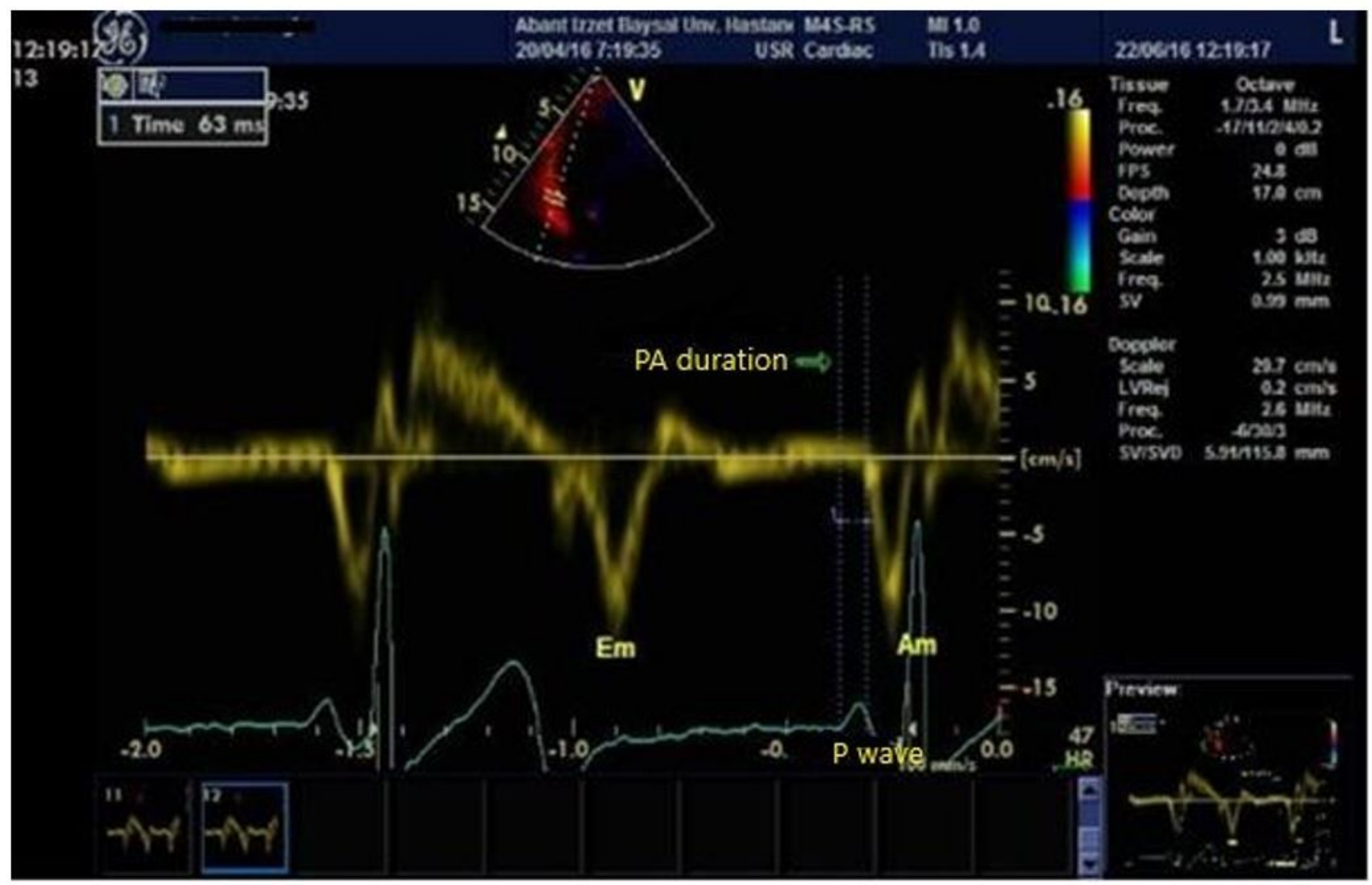


Measurement of atrial conduction time with tissue doppler echocardiography method

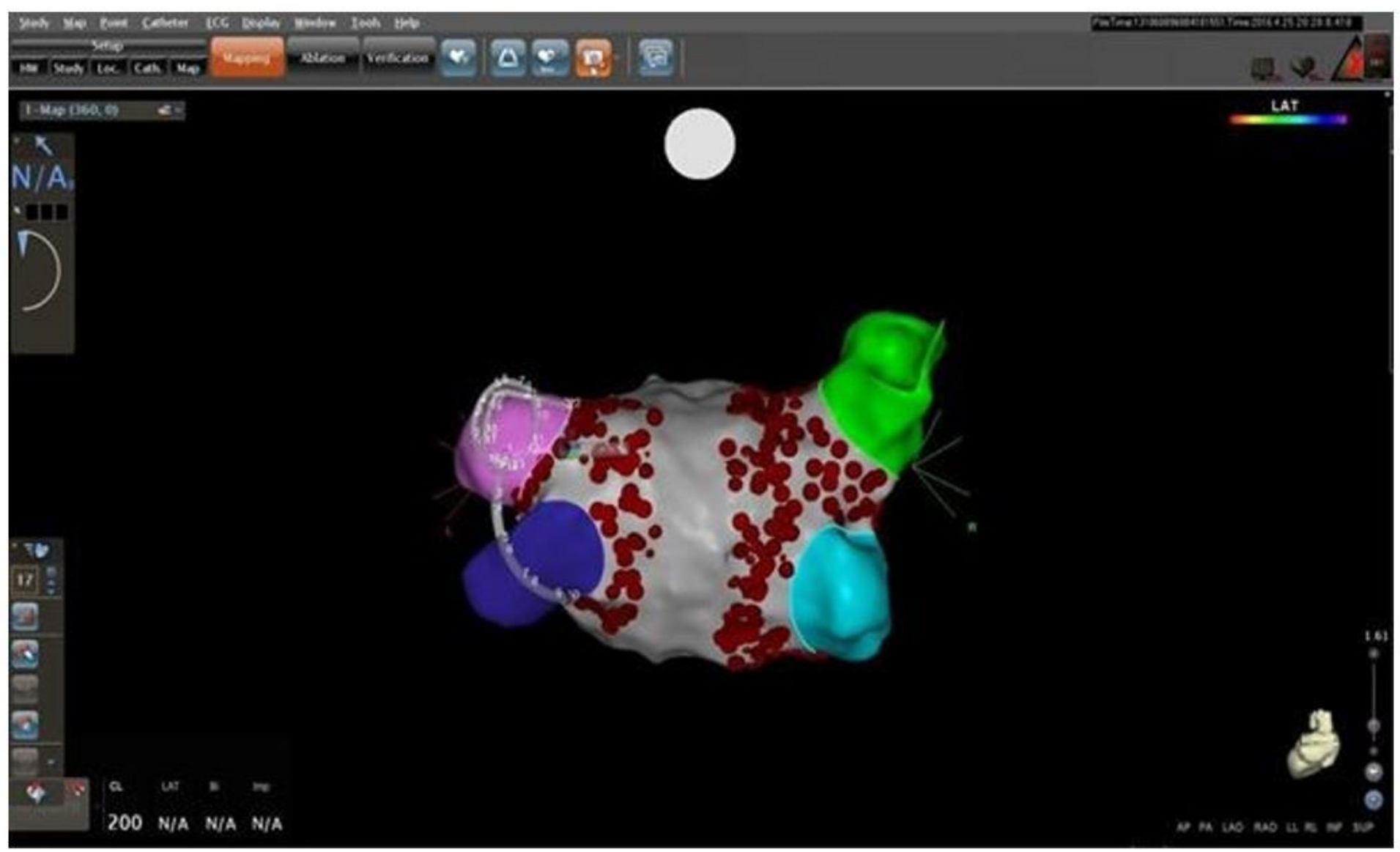

\section{Figure 2}

Pulmonary vein isolation CARTO® image 


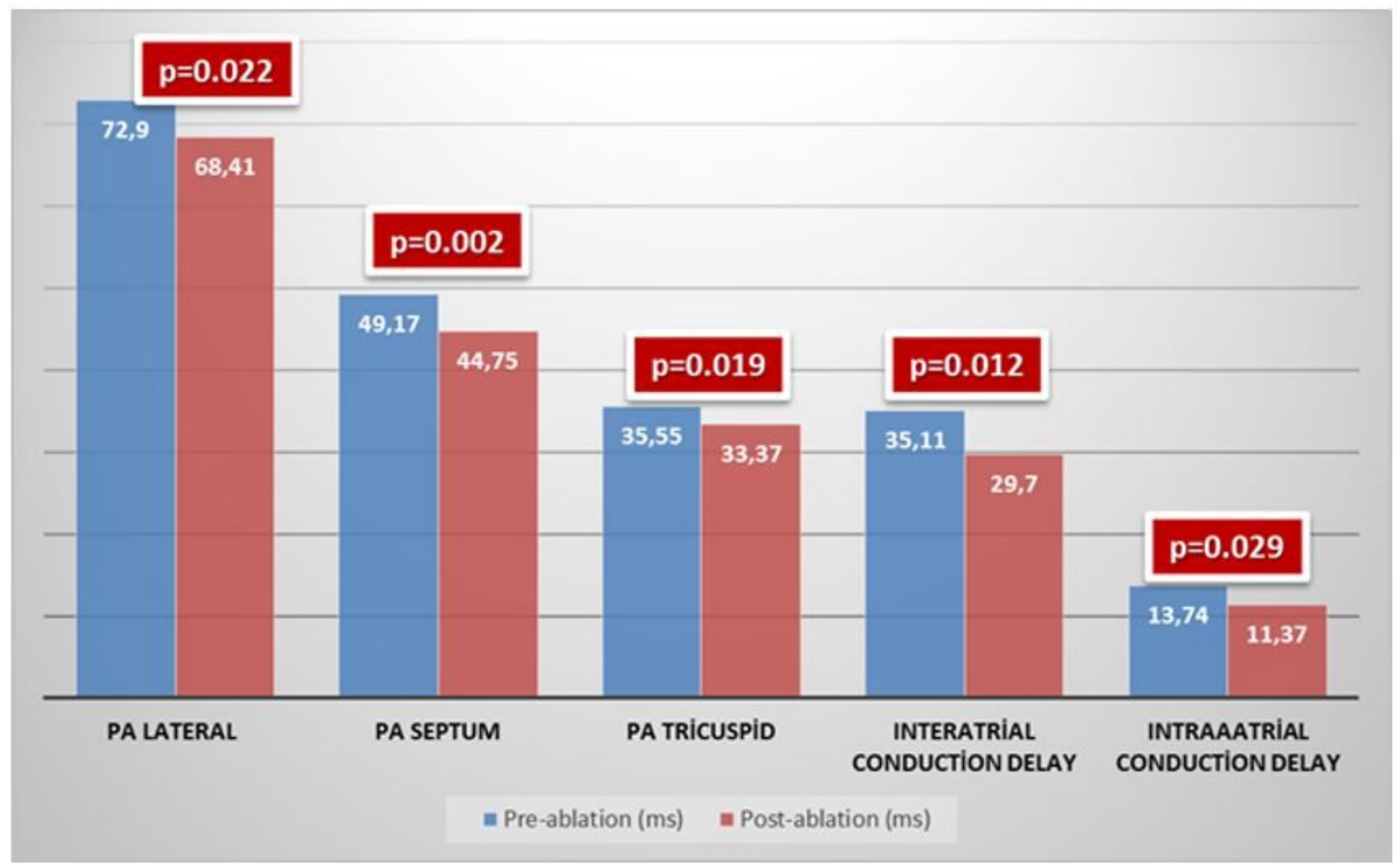

Figure 3

Comparison of atrial conduction times before and after RF ablation. 

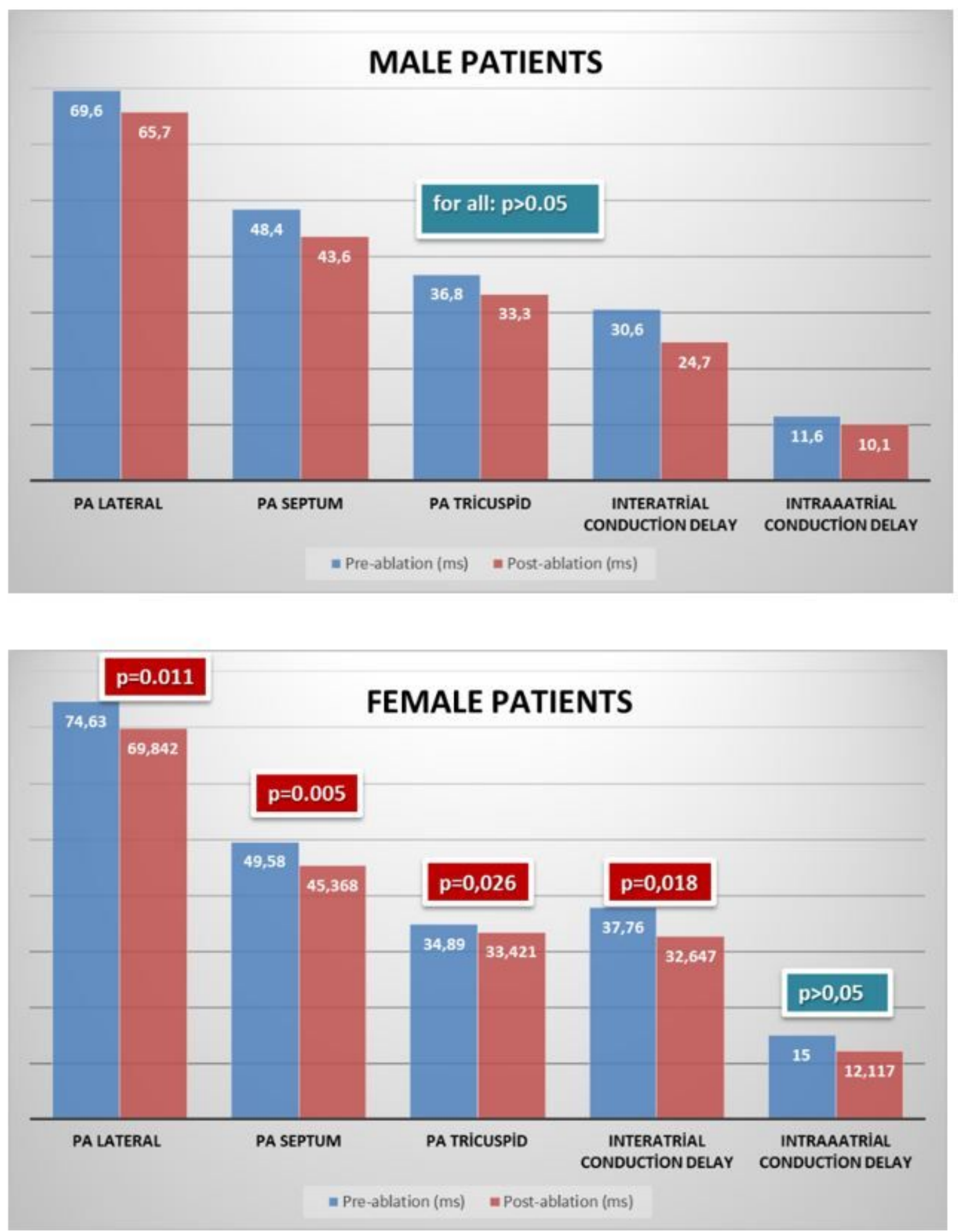

\section{Figure 4}

Comparison of pre- and post-ablation atrial conduction times according to sexes. 